\title{
Genetic Diversity and Population Structure of some Nigerian Accessions of Bambara Groundnut (Vigna subterranea (L.) Verdc) using DArT SNP Markers
}

OPEYEMI TUNDE OSUNDARE ( $\sim$ opeyemi.osundare@fuoye.edu.ng )

Federal University Oye-Ekiti https://orcid.org/0000-0001-9476-3444

\section{Benjamin 0. Akinyele}

Federal University of Technology Akure

Alexander C. Odiyi

Federal University of Technology Akure

Rajneesh Paliwal

IITA: International Institute of Tropical Agriculture

\section{Olaniyi A. Oyatomi}

IITA: International Institute of Tropical Agriculture

Michael T. Abberton

IITA: International Institute of Tropical Agriculture

\section{Research Article}

Keywords: Diversity, DArT markers, Bambara groundnut and Nigerian accessions

Posted Date: February 7th, 2022

DOI: https://doi.org/10.21203/rs.3.rs-1292086/v1

License: (1) This work is licensed under a Creative Commons Attribution 4.0 International License.

Read Full License 

subterranea (L.) Verdc) using DArT SNP Markers

Opeyemi T. Osundare ${ }^{1,2}$, Benjamin O. Akinyele ${ }^{1}$, Alexander C. Odiyi ${ }^{1}$, Rajneesh Paliwal ${ }^{2}$, Olaniyi A. Oyatomi ${ }^{2}$

Michael T. Abberton ${ }^{2 *}$

${ }^{1}$ Department of Crop, Soil and Pest management, Federal University of Technology, Akure, Nigeria

${ }^{2}$ Genetic Resources Centre, International Institute of Tropical Agriculture, Ibadan, Nigeria

\section{Abstract}

Bambara groundnut is one of the crops with inadequate molecular research to show its full potentials. Previous studies showed morphological diversity with inadequate information to confirm genetic variations. In the quest to

11 reveal the genetic potentials, deoxyribonucleic acid (DNA) of the selected accessions were extracted through leaf samples at 3 weeks old, using Dellaporta Miniprep for Plant DNA Isolation procedure. The high quality DNA was sequenced using Diversity Arrays Technology (DArT) markers to unlock diversity among Bambara groundnut of Nigerian origin. Cluster analysis (neighbor-joining clustering) of the single nucleotide polymorphisms (SNP's) were used to generate sub-population to show relatedness and differences. Seven sub-populations were generated with $5,927(50.13 \%)$ high quality DArT markers out of the 11, 821 SNPs generated. This revealed high genetic diversity existed among the selected Bambara groundnut accessions in Nigeria. This also revealed that DArT markers were highly efficient in classifying the accessions based on molecular expressions. This study also identified markers responsible for genetic variation that could facilitate the characterization of larger collections for further utilization of genetic resources and most importantly Bambara groundnut for the purpose of crop improvement.

21 Keywords: Diversity, DArT markers, Bambara groundnut and Nigerian accessions

\section{2}

\section{Introduction}

Bambara groundnut (Vigna subterranea [L.] Verdcourt, Syn: Voandzeia subterranea [L.] Thouars) is an underutilized grain legume grown in Africa, for food security (Ntundu et al., 2006). The crop is an important legume in Africa after cowpea (Vigna unguiculata [L.] Walp.) (Atoyebi et al., 2017). Molecular research provides new insight on the population structure of African Bambara groundnut germplasm which will help in conservation strategy and management of the crop (Uba et al., 2021). Published research works relating to African orphan crops emphasized on the need for more molecular research to harness the hidden potentials (Mayes et al., 2013; Ntundu et al., 2006). 
Bambara groundnut seed is regarded as a balanced food because when compared to most food legumes, it is rich in iron and its protein contains high level of lysine and methionine (Adu-Dapaah and Sangwan, 2004; Massawe et al., 2005). This promising crop is a weapon against food and nutritional insecurity ravaging in Africa. The current world population is over 7 billion, Africa accounts for over 1.2 billion and Nigeria being the most populated African country, accounts for over 200 million, with an average population growth above $1 \%$ yearly (World population prospect, 2019). The logical connective is an increasing food demands and decreasing arable land in the world, hence, increasing number of people and decreasing arable land. This, if not checked, everyone becomes vulnerable to food and nutritional insecurity. Bambara groundnut can be considered as one of the crop with inadequate molecular research to show its full potential for improvement (Ntundu et al., 2006; Massawe et al., 2005), when compared with cereal crops. Most available researches are based on agronomic characterization (Mayes et al., 2013; Goli, 1997), while some show results of tolerance to abiotic stresses (Kouassi and Zoro, 2010). Bambara groundnut is cleistogamous, highly inbreeding and has 11 pairs of chromosomes $(2 n=2 x=22)$. There are numerous Bambara groundnut accessions in the genebanks that needs to be evaluated for possible improvement in identifying traits with better performance and associated genes to the existing or identified ones. Markers based on amplified fragment length polymorphism (AFLP), simple sequence repeat (SSR) and rapid amplified polymorphic DNA markers (RAPD) have been reported to reveal genetic diversity (Atoyebi et al., 2017; Mohammed et al., 2014 ; Olukolu et al., 2012; Amadou et al., 2001) but concluded that it is essential to investigate larger diverse collections with high throughput markers to revealing comprehensive genetic diversity with associated traits. Diversity Array Technology enzymes (Wenzl et al., 2004) and a combination of DArT approaches with next generation sequencing technologies have resulted in low cost and high throughput genotyping by sequencing, showing the detection of variations in single nucleotide polymorphisms (SNP) in a genome (Kilian et al., 2012). SNP as a co-dominant marker in DArT

51 will help to unlock genetic diversity and understand the population structure of some Nigeria accessions of Bambara groundnut. This work focuses on the use of DArTseq to identify genetic diversity and associated significant genes to

53 agro-morphological variation in Bambara groundnut to facilitate the utilization of existing genetic resources for 54 enhance adaptability to climate change. 
The study was carried out at the International Institute of Tropical Agriculture (IITA), Ibadan, Nigeria and

57 International Institute of Tropical Agriculture, research station, located at the Institute of Agricultural Research and

58 Training (IAR\&T) Ikenne, Nigeria for three years. The site (Ibadan) is located on coordinate's $7.38^{\circ} \mathrm{N}$ latitude and

$593.94^{\circ} \mathrm{E}$ longitude and it is situated at elevation 181 meters above sea level. The average annual temperature is

$6026.5^{\circ} \mathrm{C}$ and about $1311 \mathrm{~mm}$ of precipitation falls annually with $81 \%$ mean relative humidity. Ikenne is on

61 coordinate's $6.87^{\circ} \mathrm{N}$ latitude and $3.71^{\circ} \mathrm{E}$ longitude and 235.2 meters above sea level, has an annual rainfall of 1200

$62 \mathrm{~mm}, 65 \%$ mean relative humidity and $21.4^{\circ} \mathrm{C}$ mean temperature respectively. Seeds of one hundred accessions of

63 Bambara groundnut were collected from the Genetic Resources Centre (GRC), of IITA in 2017 and used for the

64 field experiments (Table I). The accessions were collected from the regions of Nigeria for years and conserved in the

65 genebank of IITA for germplasm exchange.

\section{Experimental design}

67 The experiments were carried out in two locations (Ibadan and Ikenne) for three years (2017/2018, 2018/2019 and

68 2019/2020). The experiments were laid out in a Randomized Complete Block Design (RCBD) with three

69 replications and total block size was $21 \mathrm{~m}$ x $50 \mathrm{~m}$ and each plot was $1 \mathrm{~m}$ x $2.5 \mathrm{~m}$. Inter and intra row spacing was

$70 \quad 1.00 \mathrm{~m}$ and $0.25 \mathrm{~m}$ respectively. Twenty eight quantitative data were collected.

\section{DNA Extraction and Genotyping}

72 Three weeks after planting, leaf samples of each accession were collected and plant stands from which samples were

73 collected was tagged. DNA extraction was done at the Bioscience Centre, International Institute of Tropical

74 Agriculture, Ibadan following the procedure of Dellaporta Miniprep for Plant DNA Isolation (Weigel and

75 Glazebrook, 2009). DNA was quantified at $260 \mathrm{~nm}$ with a Nanodrop spectrophotometer (NANODROP 8000,

76 thermo scientific) and its quality was checked at 260/230 and 260/280 nm absorbance ratios and agarose gel

77 electrophoresis respectively. The samples were sent to Diversity Arrays Technologies commercial service Ltd.,

78 Australia (www.diversityarrays.com) for a high throughput single nucleotide polymorphism (SNP) genotyping. The

79 obtained DArT marker set was filtered on the basis of individual marker-related statistics by removing markers with

80 inappropriate quality control parameters with call rate $\leq 80 \%$ and missing data $\geq 20 \%$. The informativeness of the

81 marker was determined using the polymorphic information content (PIC). The remaining high quality markers of 5, 

(presence and absence) and were used as different entries in TASSEL 5.0 software to construct neighbor join phylograms. The genome wide association study (GWAS) was conducted using the phenotypic data means for the three years (2017-2020), using the GLM and MLM-PCA batch commands in Tassel 5.0 software (Bradbury et al., 2007). Marker-trait associations (MTAs) were analyzed for the quantitative traits using a generalized linear model

87 and a population stratification (structure) correction based on principal component analysis (PCA) (Price et al., 2006). The significance of associations between SNPs and traits was based on the threshold $\mathrm{P}<1.68 \times 10^{-4}$, calculated by dividing 1 by the total number of SNPs (5927) in the analysis (Li et al., 2016).

\section{Analysis of Population Structure}

Clustering approach was used to estimate the real number of subpopulations with correlated allele frequencies based on marker data by neighbor-joining method using TASSEL 5.0 software (Bukler Lab for Maize genetics and diversity, 2018). Each genotype was assigned to subpopulation based on its membership probability.

\section{2-Dimensional principal component analysis (2DPCA matrix quadrant)}

2DPCA matrix quadrants (PC 1 and PC 2) were also carried out to reveal the distribution of the accessions based on their morphological traits expression. Classification based on 2-Dimensional principal component analysis is based on 2D image matrix, so the image matrix does not need to be transformed into a vector prior to feature extraction. Therefore, an image is constructed with the covariance matrix and its eigenvectors derived for image feature extraction which uses the first two highest contributing principal components (PC 1 and PC 2) to ensure that traits of the highest importance in contribution to variation are captured based on their influence and an image of subgroup membership of the genetic resources were constructed to reveal variations (Yanai and Ishii, 2010).

\section{RESULTS}

\section{Population stratification}

DArTseq showed that 100 accessions of Bambara groundnut were grouped into seven clusters (Table II and Figure 
cluster II had nineteen accessions, cluster III had six accessions, cluster IV had nine accessions, cluster V had fourteen accessions, cluster VI had twelve accessions and cluster VII had twelve accessions, while the remaining 7 accessions had mixed allelic patterns that could not be assigned to any of the clusters or probably could not produce enough information to meet the quality check. The accessions were clustered in accordance with relatedness and differences in their genetic constitution. Accessions in the same cluster reflect genetic relationships and most diverse accessions were out grouped.

\section{Comparison between population structure as revealed by DArT markers and 2DPCA in three years}

Figure 1, Table II and Figure 2 revealed the accessions that were genetically and morphologically grouped in the same or different cluster as revealed by DArTseq or 2DPCA quadrant. This investigation is necessary to ensure if the observed morphological variation in the selected accessions were genetic or occurred as a result of chance. In cluster or subpopulation 1 based on DArTseq, accessions TVSu-333, TVSu-336, TVSu-2100, TVSu-2105, TVSu2109, TVSu-589, TVSu-2106, TVSu-670 were classified in the same 2DPCA matrix quadrant (Q2), based on traits contribution to morphological diversity, meaning that the aforementioned accessions were not only morphologically related but also genetically related. In cluster IV based on DArTseq, accessions TVSu-14, TVSu-261, TVSu-12, TVSu-1242, TVSu-1252 and TVSu-365 were classified in the same 2DPCA matrix quadrant (Q1) based on morphological grouping, cluster II based on DArTseq showed that accession TVSu-262 and TVSu-256 were also morphologically clustered in quadrant 4 (Q4). Cluster I, II, III, V and VI also showed that accessions TVSu-269, TVSu-127, TVSu-263, TVSu-173, TVSu-181, TVSu-178, TVSu-1222, TVSu-659, TVSu-2108 and TVSu-355 were grouped in quadrant $3(\mathrm{Q} 3)$ which indicated interrelationship in the population. This revealed that expression of morphological traits might be genetic and also indicated genetic similarities in accessions that were grouped in the same cluster and quadrant.

\section{Allele frequencies and proportion based on Single nucleotide polymorphism (SNPs) genotyping}

129 The selected accessions used in this study showed allelic variation across multiple loci and such differences in the 130 allele frequencies produced genetic differentiation in the population. However, the values of proportion of alleles 131 and diploids observed were small and allele frequencies very similar. Table IV showed that the addition of the interactions and frequency distribution of the diploid used was the same with the 'called' SNPs $(5,927)$ in this 
study, C:T (856, 0.14442), G:A (805, 0.13582), T:C (783, 0.13211), A:G (776, 0.13093), T:A (293, 0.04943), G:C

134

135 (266, 0.04488), A:T (265, 0.04471), C:G (261, 0.04404), A:C (251, 0.04235), C:A (245, 0.04135), G:T (244, 0.04117), T:G (217, 0.03661), G:G (172, 0.02902), C:C (168, 0.02834), A:A (163, 0.0275) and T:T (162, 0.02733). Alleles percentage in the SNPs (C, G, A and T) ranged from $0.23-0.24$ (23 - 24 percent), C and G had 0.24 (24 percent) while A and T had 0.23 (23 percent) in the SNPs.

\section{Marker Data}

The filtered DArTseq genotyping produced 5, 927SNPs from 98 lines. In the 5, 927 SNP filtered, 4, 095 SNP was unaligned on 'Mung bean genome'. In the analysis 1,832 SNPs (30.90\%) aligned on 'Mung bean genome'. Chromosome 1 had 158 aligned markers (8.62\%), chromosome 2 had 119 aligned markers (6.49\%), chromosome 3 had 120 aligned markers (6.55\%), chromosome 4 had 86 aligned markers (4.69\%), chromosome 5 had 203 aligned markers (11.08\%), chromosome 6 had 148 aligned markers (8.07\%), chromosome 7 had 203 aligned markers (11.08\%), chromosome 8 had 199 aligned markers (10.86\%), chromosome 9 had 98 aligned markers (5.34\%), chromosome 10 had 132 aligned markers (7.20\%) and chromosome 11 had 134 aligned markers (7.31\%) while the remaining markers were scaffolds. General linear model (GLM) revealed 1,504 markers were significant. Mixed linear model (MLM) revealed 611 markers were significant and MDS revealed 3589 markers were significant in the sequence at $-\log _{10}{ }^{4}$ for 21 traits. Total unfiltered SNP was 11, 821 and 3,387 SNP (28.65\%) aligned on Mung bean genome. Genome-wide association studies indicated significant SNP markers that revealed quantitative traits loci (QTLs) associated with phenotypic traits. However, many of the quantitative traits used in this study associated with more than one marker. Table V revealed that marker 24383534|F|0-6:G>A-6:G>A controlled Chaff weight, plant height, shelled harvest per Plot and shelling percentage. Marker 37320448|F|0-15:G>A-15:G>A also controlled Chaff weight, plant height, shelled harvest per Plot and shelling percentage. Marker 24383752|F|0-61:G>T-61:G>T controlled 100-seed weight, Number of pods per plot, shelled harvest per plot and shelling percentage. Marker 24346601|F|0-67:T>C-67:T>C only controlled number of days to flowering. Marker 4183841|F|0-29:A>G-29:A>G only controlled number of flower per peduncle. Marker 24383752|F|0-61:G>T-61:G>T controlled number of pods per area, shelled harvest per plot, shelling percentage and 100-seed weight. Marker 24385974|F|0-26:C>G-26:C>G controlled number of seed per pod, terminal leaflet length and terminal leaflet width. Marker 24346965|F|0-27:C>T27:C $>\mathrm{T}$ controlled pod length and terminal leaflet width. Marker 24384331|F|0-20:G>A-20:G>A only controlled 
pod width. Marker 27640259|F|0-9:A>G-9:A>G controlled petiole length, terminal leaflet length and terminal leaflet width. Marker 27641016|F|0-24:G>T-24:G>T controlled plant height, shelled harvest per plot, shelling percentage, terminal leaflet length, terminal leaflet width and petiole length. Marker 27641679|F|0-9:C >T-9:C >T only controlled seed length. Marker 24383723|F|0-24:C>T-24:C>T controlled only seed width. Marker 4181685|F|0-19:T>A19:T>A controlled seed weight per plot and yield per hectare. Markers 24383752|F|0-61:G>T-61:G>T controlled Shelled harvest per plot, Shelling percentage, 100-seed weight and number of pods per area. Marker 24383752|F|061:G>T-61:G>T controlled Shelled harvest per plot, Shelling percentage, 100-seed weight and number of pods per area. Marker 24346321|F|0-14:G>A-14:G>A controlled terminal leaflet length and terminal leaflet width. Marker 24346321|F|0-14:G>A-14:G>A controlled terminal leaflet width and terminal leaflet length. Marker 4181685|F|019:T>A-19:T>A controlled seed weight per plot and yield per hectare. Marker 24346252|F|0-35:A>G-35:A>G only controlled yield per plant. MLM revealed 611 significant markers with associated phenotypic trait. Nineteen of the

17121 phenotypic traits had significant markers associated with the traits in the analysis. Chaff weight per plot had two 172 significant markers associated, 100-seed weight had 11 significant markers associated, number of flower per 173 peduncle had only 1 significant marker associated, number of days to flowering had 5 significant markers associated, number of pods per plot had 9 significant markers associated, number of seed per pod had 32 significant 175 markers associated, pod length had 45 significant markers associated, pod width had 3 significant markers 176 associated, petiole length had 4 significant markers associated, plant height had 4 significant markers associated, 177 seed length had 7 significant markers associated, seed width had 25 significant markers associated, seed weight per 178 plot had 5 significant markers associated, shelled harvest per plot had 13 significant markers associated, shelling 179 percentage per plot had 13 significant markers associated, terminal leaflet length had 119 significant markers associated, terminal leaflet width had 179 significant markers associated, yield per hectare had 3 significant markers

181 associated and yield per plant had 131 significant markers associated. In the associated traits, terminal leaflet width 182 had the highest associated markers, followed by yield per plant and terminal leaflet length respectively. Figure 3-8 showed manhattan plots of $-\log _{10} 4$ vs. chromosomal position of SNP markers associated with some of the phenotypic

184 traits. A red line represents the significant threshold $\left(-\log _{10}{ }^{4}\right)$ and higher chromosomal positions above the threshold 185 showed loci significance to variations.

\section{Discussion}


DArTseq based on single nucleotide polymorphisms (SNPs) shown seven subpopulations, indicating wide genetic variation. This reiterated the suitability of DArT high throughput sequencing for diversity studies. Olukolu et al. (2012) also reported genetic diversity for Bambara groundnut accessions using DArT markers. DArTseq revealed that accessions formed different subpopulation, indicating high genetic variation in the selected population. DArTseq also revealed some accessions in the same subpopulation; this might be due to related accession ancestry or resulting from generational out-crossing, hence, related genetic constitution. Highest number of accessions (26) in the subpopulation structure (cluster I), indicated that the highest genetic relationship existed in that subpopulation structure. Cluster III had the lowest number of accessions (6) in the subpopulation structure, indicating that the lowest genetic relationship existed in that subpopulation structure. This was also reported by Rex Bernado (2020) that using molecular data is a veritable tool in unlocking diversity. This indicated that accessions clustered in the same group have genetic relationship in the population. The subsequent show of diversity among the selected accessions shown in different subpopulation (cluster I-VII), in relation to variation expressed also indicated dissimilarities in the genetic makeup of the population. The consistency in the grouping of the accessions as expressed in the clusters indicated that the DNA bases expressed in the genetic makeup form the basis of heredity, hence, responsible for traits transfer to sustaining diversity in Bambara groundnut. Alleles percentage variation

202 showed $\geq 1 \%$ genetic variation in the population data, where Cytosine (C), Guanine (G), Adenine (A) and Thymine 203 (T) ranged from (23 - $24 \%), \mathrm{C}$ and G had (24 \%) while A and T (23\%) in the SNPs, which indicated large source of sequence variation in Bambara groundnut. Hence, SNPs are confirmative mean to reveal genetic diversity.

205 Cytosine and Guanine are the most common bases in the regions of the genome as well as in the genes with over $20624 \%$ of the genetic makeup. This indicated that the differing allele frequencies are responsible for genetic variations.

207 This was also supported by Matthew et al. (2004), who reported that SNPs with MAF greater than 5\% in 208 populations are responsible for genetic variations. Genome-wide Association Studies (GWAS) identified stable loci 209 for 19 phenotypic traits; this indicated that these loci may be veritable tools in developing new cultivars with high 210 yield and yield stability. The associated significant markers indicated high level of genetic variance in Bambara 211 groundnut. This supports the findings of Choudhary et al. (2013); Huynh et al. (2013); Aliyu et al. (2016) that 212 molecular genetic diversity analyses aid breeding decisions in crop species. The differing significant marker sites 213 indicated variations in the haplotypes and identified exons. Stadler (2009); Somta et al. (2011) also reported high 214 level of allelic diversity in Bambara groundnut. However, some of the significant markers associated to more than 
one trait confirmed pleiotropy or linkage of the genes. The alignment of the sequence polymorphic markers on 'Mung bean genome' by some of the significant markers associated with phenotypic traits indicated that

217 chromosome positions 5, 7 and 8 had the strongest associations with the phenotypic traits and is crucial to be 218 considered in genetic variation of Bambara groundnut which accounted for $33.02 \%$ of variations identified through

219 the chromosomes. Similar result was also reported by Gahlaut et al. (2019) in wheat. The alignment of the Bambara 220 groundnut sequence on the "Mung bean genome also indicated that 1,832 SNPs (30.90\%) aligned, nevertheless, 221 some of the markers were less informative and could not be assigned to chromosome locations in the sequence, 222 hence tagged scaffolds, this reiterated the result of Ho et al. (2017) that $48 \%$ of Bambara groundnut sequence 223 marker tags were mapped on the 'Mung bean genome'. GWAS also indicated that many of the phenotypic traits are 224 controlled by more than one marker in different or the same chromosomal positions, meaning that the phenotypic 225 traits are polygenic; they are determined by the interaction between several alleles. This further reiterated the fact 226 that each marker compared the trend in the quantitative traits to the trend in the genotypes and identify loci causing 227 variation in the genome. Further observation showed that some of the markers coded for more than one trait, i.e. 228 single marker coding for two or more phenotypic traits, this indicated the pleiotropic nature of genes. This was also 229 supported by Wang et al. (2008); Yongsheng Chen (2011) who corroborated that genetic trait correlation can be due 230 to pleiotropy or linkage disequilibrium. Although, discussion of genetic traits correlation is controversial but 231 Falconer (1960) resolved that pleiotropy is possible to be the reason for traits association than linkage. In contrast 232 Mather and Jinks (1971) advocated that associations between traits are due to linkage. Further observation in this 233 study as indicated at the sequence polymorphic level, showed that genetic traits association is due to pleiotropy. This 234 was also supported by sibov et al. (2003); Zygier et al. (2005); Chen et al. (2008) and Wang et al. (2008). This study 235 further revealed that some genetically associated traits controlled by the same sequence polymorphic markers and 236 chromosome position are tightly correlated.

\section{Conclusion}

238 This study confirmed DArT genotyping based on SNP is effective to detect the genetic diversity and population structure of Bambara groundnut accessions. DArT markers used also revealed wide range genetic diversity and

240 making the selected population a potential source for Bambara groundnut improvement. Selection of high 241 contributing morphological traits in Bambara groundnut is genetic. The differing identified subpopulation of 
242 Bambara groundnut could be used in breeding improved cultivars in enhancing responsiveness to climate change.

243 This could further be reaffirmed by using other high throughput markers in future research.

\section{$244 \quad$ Funding}

245 This paper was financed by The Global Crop Diversity Trust (Crop Trust), through the Consortium of International 246 Agriculture Research (CGIAR) and the Genetic Resources Centre, International Institute of Tropical Agriculture, 247 Ibadan, Nigeria.

\section{Acknowledgement}

249 Appreciation to the Genetic Resources Centre, International Institute of Tropical Agriculture, Ibadan, Nigeria for the 250 research fellowship offered during this research work and their technical assistance throughout the period.

251 Data Availability

252 The data used to support the findings of this research are available from the corresponding author upon request.

\section{Conflict of interest}

254 The authors declare that we have no conflict of interest.

\section{$255 \quad$ References}

256 Adu-Dapaah HK, Sangwan RS. Improving Bambara groundnut productivity using gamma irradiation and 257 in vitro techniques. Afr. J Biotechnol. 2004; 3:260-5

258 Aliyu, S. Massawe, F. and Mayes, S. 2016. Genetic diversity and population structure of Bambara groundnut (Vigna subterranea (L.) Verdc.): synopsis of the past two decades of analysis and implications for crop improvement programmes. Genet Resour Crop Evol 63:925-943 DOI 10.1007/s10722-016-0406-z

261 Amadou H.I., Bebeli P.J., and Kaltsikes P.J. 2001. Genetic diversity in Bambara groundnut (Vigna subterranea L.) germplasm revealed by RAPD markers. Genome, 44(6): 995-999 
selected African Accessions of Bambara Groundnut (Vigna subterranea (L.) Verdc.). International Journal of Plant Research 2017, 7(2): 29-35 DOI: 10.5923/j.plant.20170702.01

Bradbury PJ, Zhang Z, Kroon DE, Casstevens TM, Ramdoss Y and Buckler ES .2007. TASSEL: software for association mapping of complex traits in diverse samples. Bioinformatics (Oxford, England) 23: 26332635

Bukler Laboratory for Maize genetics and diversity. 2018. TASSEL software for diversity analysis. NY

Chen J, Xu L, Cai Y, Xu J .2008. QTL mapping of phosphorus efficiency and relative biologic characteristics in maize (Zea mays L.) at two sites. Plant Soil 313: 251-266

Choudhary G, Ranjitkumar N, Surapaneni M, Deborah AD, Anuradha G, Siddiq EA, Vemireddy LR .2013. Molecular genetic diversity of major Indian rice cultivars over decadal periods. PLoS ONE. doi:10.1371/journal.pone.0066197

Falconer DS .1960. An Introduction to Quantitative Genetics, Ronald Press, New York

Gahlaut, V., Jaiswal, V., Singh, S., Balyan, H. S. and Gupta, P. K . 2019. Multi-Locus Genome Wide Association Mapping for Yield and Its Contributing Traits in Hexaploid Wheat under Different Water Regimes Scientific Reports 9:19486 https://doi.org/10.1038/s41598-019-55520-0

Goli, A.E. 1997. Bibliograghical Review. In 'Proc. Workshop on conservation and Improvement of Bambara Groundnut (Vigna subterranea (L.) Verdc.)' IPGRI and IPK, Harare, Zimbabwe. P.4-10

Hailegiorgis, D., Mesfin, M. and Genet, T. 2011. Genetic Divergence analysis on some Bread Wheat Genotypes Grown in Ethiopia. Journal of Central European Agric. 12 (2):344-352

Huynh B-L, Close TJ, Roberts PA .2013. Gene pools and the genetic architecture of domesticated cowpea. Plant Genome. doi:10.3835/plantgenome2013.03.0005

IPGRI, IITA, BAMNET .2000. Descriptors for Bambara groundnut (Vigna subterranea) International Institute of Tropical Agriculture, Ibadan, Nigeria/International Plant Genetic Resources Institute and International Bambara Network, Germany, ISBN:92-9043-461-9 
Kilian, A., Wenzl, P., Huttner, E., Carling, J., Xia, L., Blois, H. 2012. Diversity Arrays Technology: A generic genome profiling technology on open platforms, in Data production and analysis in population Genomics. Eds. Pompanon, F., Bonin, A. (Totowa, NJ: Humana press), 67-89. Doi:10.1007/978-1-61779-870-2_5

Kouassi, N.J. and Zoro I.A. 2010. Effect of sowing density and seed bed type on yield and yield components in Bambara groundnut (Vigna subterranea (L.) Verdc.) in Woodland Savannas of Cote D'Ivoire. Experimental Agriculture 46 (1). P. 99-110

Kumar, A., Gupta, T., Berzsenyi, S., Giangrande, A. 2015. N-cadherin negatively regulates collective Drosophila migration through actin cytoskeleton remodeling. J. Cell Sci. 128 (5):900-912

Li F, Chen B, Xu K, Gao G, Yan G, Qiao J, Li J, Li H, Li L, Xiao X and Zhang T (2016) A genome-wide

Mather K and Jinks JL .1971. Biometrical Genetics, 2nd edition, Chapman and Hall, London

Matthew R. Nelson, George Marnellos, Stefan Kammerer, Carolyn R. Hoyal, Michael M. Shi, Charles R. Cantor and Andreas Braun .2004. Large-Scale Validation of Single Nucleotide Polymorphisms in Gene Regions. Genome Res. 14 (8): 1664-1668. Doi: 10.1101/gr.2421604

Mayes, S., Basu, S., Molosiwa, O. and Redjeki, E. 2013. Molecular analysis of Bambara groundnut, an underutilized testis-specific, recently evolved, clustered miRNA in Drosophila. RNA Vol. 20 (8):1195-1209 to drought tolerance. Field Crop Research 123 (1):10-18 
Ntundu W.H., Shillah, S.A., Marandu, W.Y. and Christiansen, J.L. 2006. Morphological Diversity of Bambara

Groundnut [Vigna subterranea (L.) Verdc.] Landraces in Tanzania. Genetic Resources and Crop Evolution 53(2):367-378. Doi: 10.1007/s10722-004-0580-2

Olukolu, B., Mayes, S., Stadler, F., Nyat, Q., Fawole I., Dumet D., Azam-Ali, S., Abbott A., Kole C., 2012. Genetic diversity in Bambara groundnut (Vigna subterranea (L.) Verdc.) as revealed by phenotypic descriptors and DArT marker analysis. Genetic Resources and Crop Evolution 59(3):347-358. Doi:10.1007/S10722-0119686-5

Price AL, Patterson NJ, Plenge RM, Weinblatt ME, Shadick NA and Reich D .2006. Principal components analysis corrects for stratification in genome-wide association studies. Nature Genetics 38: 904-909.

Ravishanker, D., Rajora, A.K., Greco, F. and Osborn, H.M. 2013. Flavonoids as prospective compounds for anticancer therapy. Int. J. Biochem. Cell Biology 45(12):2821-31.

Rex Bernado. 2020. Reinventing quantitative genetics for plant breeding: something old, something new, something borrowed, something BLUE. The genetics society. Heredity. https://doi.org/10.1038/s41437-020-0312-1

SAS. Statistical Analysis System, version 9.4 edition .2017. SAS User’s guide. SAS Institute Inc, Cary

Shegro, A.G., Rensburg, W.S., Adebola, P. 2013. Assessment of genetic variability in Bambara groundnut (Vigna subterranea (L.) Verdc) using morphological quantitative traits. Academia Journal of Agric. Research Vol. 1(3): p.45-51. ISSN:2315-7739

Sibov ST, de Souza CL Jr, Garcia AA, Silva AR, Garcia AF, Mangolin CA, Benchimol LL, de Souza AP .2003. Molecular mapping in tropical maize (Zea mays L.) using microsatellite markers. 2. Quantitative trait loci (QTL) for grain yield, plant height, ear height and grain moisture. Hereditas 139: 107-115

Somta, P., Chankaew, S., Rungnoi, O., Srinives P. 2011. Genetic diversity of Bambara groundnut (Vigna subterranea (L.) Verdc.) as assessed by SSR markers. Genome 54 (11):898-910

Stadler F. 2009. Analysis of differential gene expression under water-deficit stress and genetic diversity in Bambara 
groundnut [Vigna subterranea (L.) Verdc.] using novel high-throughput technologies. PhD Thesis, Technische Universita"t München, Germany

Subramanian, A. and Subbaraman, N. 2010. Hierarchical cluster analysis of genetic diversity in Maize germplasm. Electronic Journal of Plant Breeding 1(4):431-436

Uba CU, Oselebe HO, Tesfaye AA, Abtew WG .2021. Genetic diversity and population structure analysis of bambara groundnut (Vigna subterrenea L) landraces using DArT SNP markers. PLoS ONE 16(7): e0253600 https://doi.org/10.1371/journal.pone.0253600

Wai Kuan Ho, Hui Hui Chai, Presidor Kendabie, Nariman Salih Ahmad, Jaeyres Jani, Festo Massawe, Andrzej Kilian and Sean Mayes. 2017. Integrating genetic maps in Bambara groundnut [Vigna subterranea (L) Verdc.] and their syntenic relationships among closely related legumes. BMC Genomics 18:192. DOI $10.1186 / s 12864-016-3393-8$

Wang L, Zhang L, Zhao C, Shan F, Tian Z, Li G .2008. QTL mapping of Flag leaf stage and heading date of wheat. Molecular plant breeding 6: 689-694

Weigel, D. and Glazebrook, J. 2009. Quick miniprep for plant DNA isolation. Cold spring harbor protocols.

$$
\text { doi:10.1101/pdb.prot5179 }
$$

Wenzl, P., Carling, J., Kudrna, D., Jaccoud, D., Huttner, E., Kleinhofs, A., et al. 2004. Diversity Arrays Technology

Yanai, H. and Ishii, H. 2010. International Encyclopedia of Education on Principal component Analysis. Third edition. ISBN: 978-0-08-044894-7. Elsevier Science

353 Yongsheng Chen .2011. pleiotropic effects of genes involved in cell wall lignification on agronomic characters. A dissertation submitted to the graduate faculty in partial fulfillment of the requirements for the degree of Doctor of philosophy, Iowa State University, Ames, Iowa 
Figures

\section{Figure 1}

Please See image above for figure legend.

\section{Figure 2}

Please See image above for figure legend.

\section{Figure 3}

Please See image above for figure legend.

\section{Figure 4}

Please See image above for figure legend. 
P-Values by Chromosome for BLUE_TLWmm
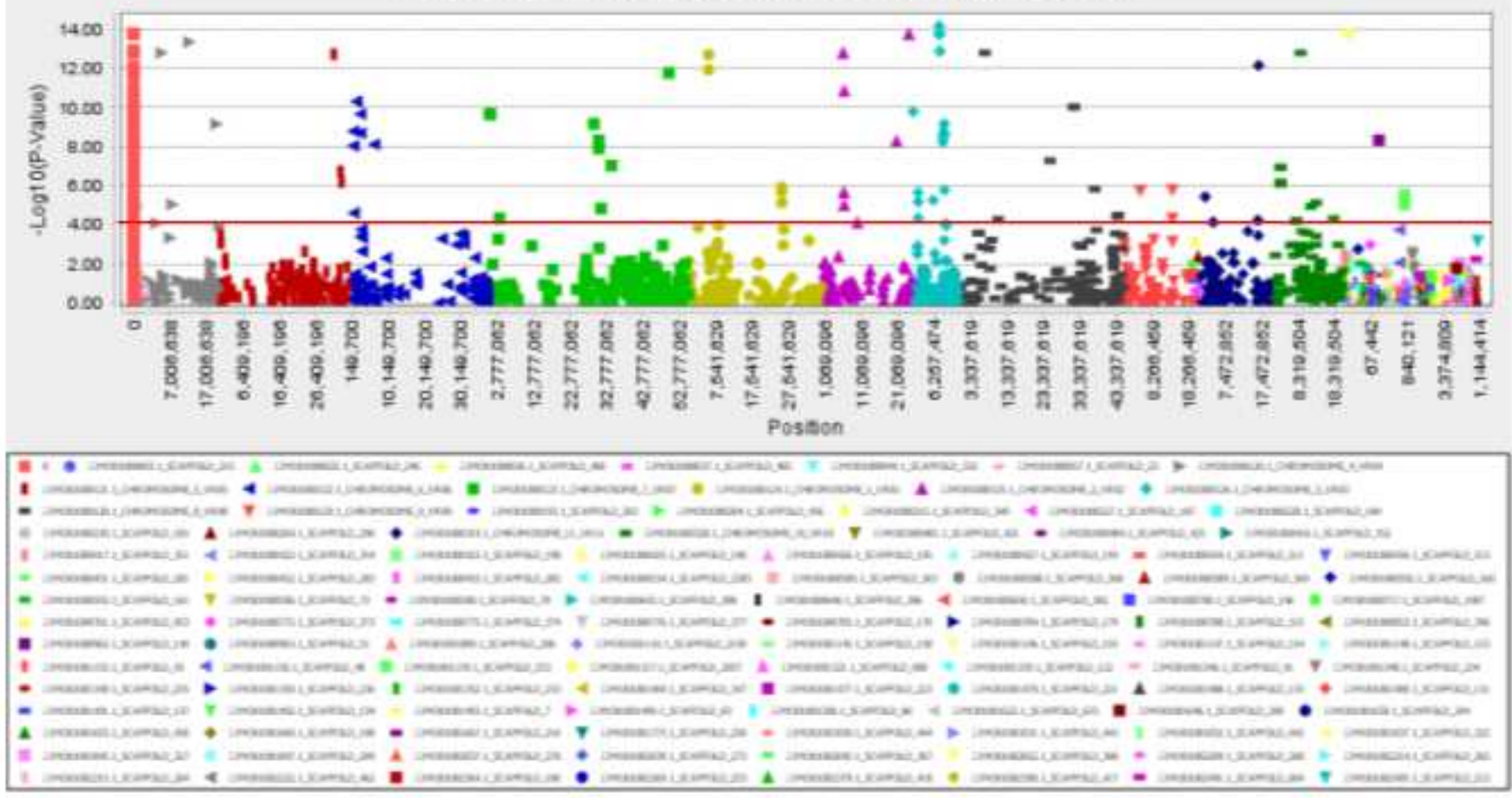

Fig.5 Manhattan plots of $-\log _{10} 4$ vs. chromosomal position of SNP markers associated with

Terminal leaflet width (TLW). A red line represents the significant threshold $\left(-\log _{10}{ }^{4}\right)$

Figure 5

Please See image above for figure legend. 


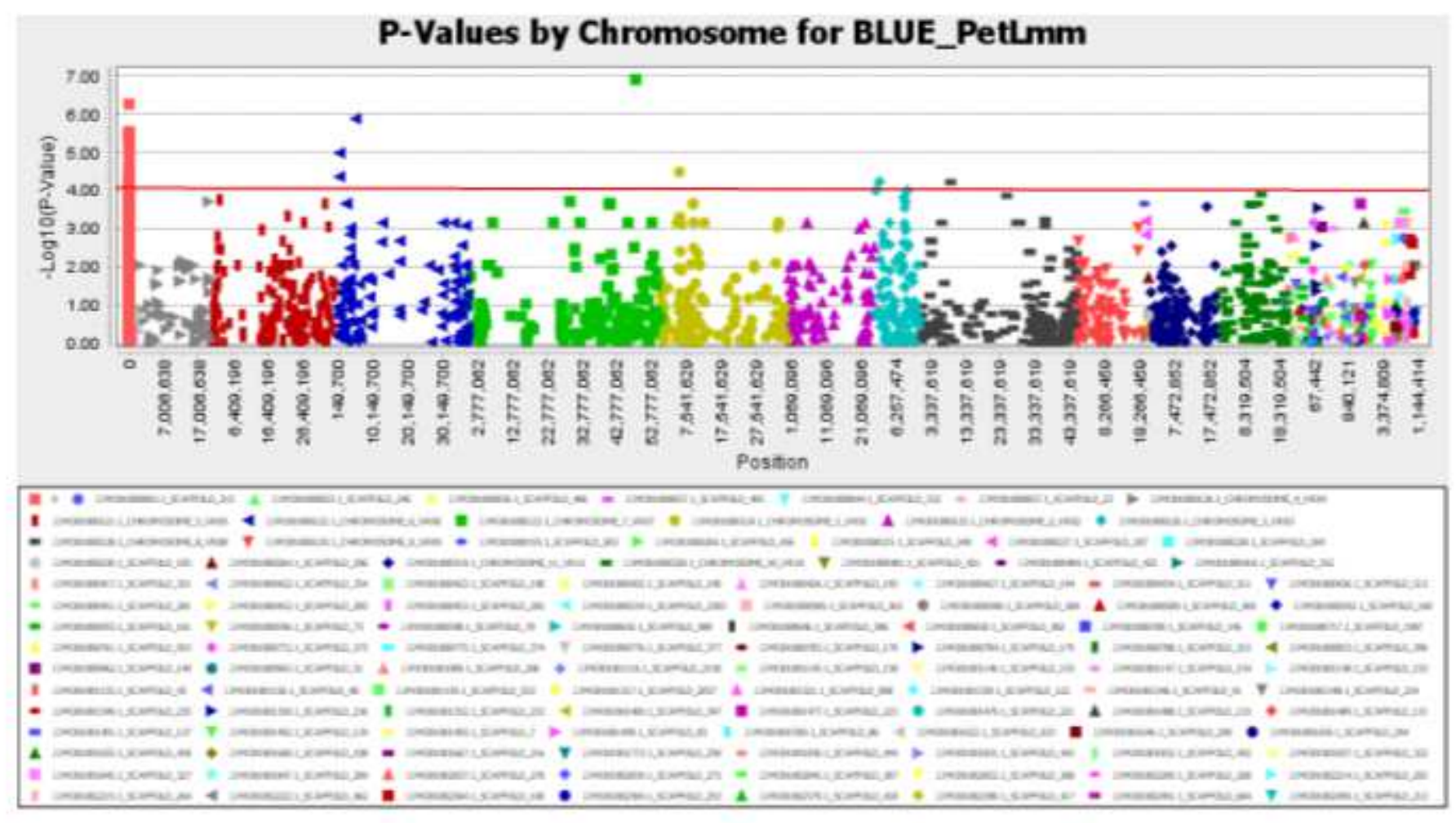

Fig.6 Manhattan plots of $-\log _{10} 4$ vs. chromosomal position of SNP markers associated with petiole length (PetL mm). A red line represents the significant threshold $\left(-\log _{10} 4\right)$

Figure 6

Please See image above for figure legend.

Figure 7

Please See image above for figure legend. 


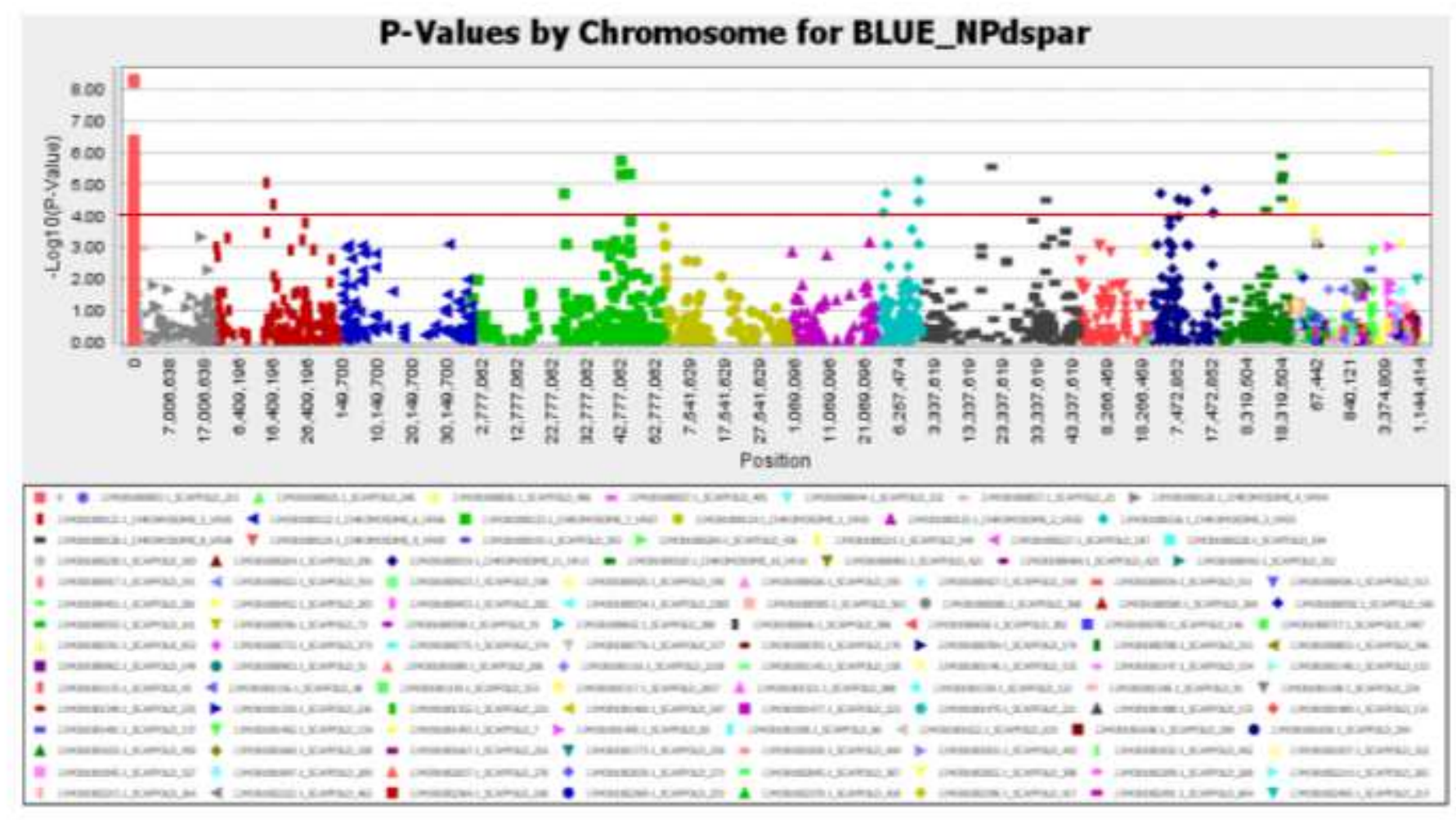

Fig.8 Manhattan plots of $-\log _{10} 4$ vs. chromosomal position of SNP markers associated with number of pods per plot (NPdspar). A red line represents the significant threshold $\left(-\log _{10}{ }^{4}\right)$

Figure 8

Please See image above for figure legend. 